OPEN ACCESS

Edited by: Ariella Hanker,

University of Texas Southwestern Medical Center, United States

Reviewed by: Miranda Clements, National Institutes of Health $(\mathrm{NIH})$, United States Shereen Elazzazy, Hamad Medical Corporation, Qatar

*Correspondence: Li Zhu

zhuli8@yeah.net

${ }^{\dagger}$ These authors have contributed equally to this work

Specialty section:

This article was submitted to Women's Cancer,

a section of the journal

Frontiers in Oncology

Received: 04 July 2020 Accepted: 03 November 2020 Published: 02 December 2020

Citation:

Liu D, Wu J, Lin C, Andriani L, Ding S, Shen K and Zhu L (2020) Breast Subtypes and Prognosis

of Breast Cancer Patients

With Initial Bone Metastasis:

A Population-Based Study.

Front. Oncol. 10:580112.

doi: 10.3389/fonc. 2020.580112

\section{Breast Subtypes and Prognosis of Breast Cancer Patients With Initial Bone Metastasis: A Population-Based Study}

\author{
Deyue Liu ${ }^{\dagger}$, Jiayi $\mathrm{Wu}^{\dagger}$, Caijin Lin, Lisa Andriani, Shuning Ding, Kunwei Shen and Li Zhu* \\ Department of General Surgery, Comprehensive Breast Health Center, Ruijin Hospital, Shanghai Jiaotong University School \\ of Medicine, Shanghai, China
}

Background: Metastatic breast cancer (MBC) is a highly heterogeneous disease and bone is one of the most common metastatic sites. This retrospective study was conducted to investigate the clinical features, prognostic factors and benefits of surgery of breast cancer patients with initial bone metastases.

Methods: From 2010 to 2015, 6,860 breast cancer patients diagnosed with initial bone metastasis were analyzed from Surveillance, Epidemiology, and End Results (SEER) database. Univariate and Multivariable analysis were used to identify prognostic factors. A nomogram was performed based on the factors selected from cox regression result. Survival curves were plotted according to different subtypes, metastatic burdens and risk groups differentiated by nomogram.

Results: Hormone receptor (HR) positive/human epidermal growth factor receptor 2 (HER2) positive patients showed the best outcome compared to other subtypes. Patients of younger age ( $<60$ years old), white race, lower grade, lower $T$ stage $(<=T 2)$, not combining visceral metastasis tended to have better outcome. About $37 \%(2,249)$ patients received surgery of primary tumor. Patients of all subtypes could benefit from surgery. Patients of bone-only metastases (BOM), bone and liver metastases, bone and lung metastases also showed superior survival time if surgery was performed. However, patients of bone and brain metastasis could not benefit from surgery $(p=0.05)$. The $\mathrm{C}$-index of nomogram was 0.66 . Cutoff values of nomogram point were identified as 87 and 157 points, which divided all patients into low-, intermediate- and high-risk groups. Patients of all groups showed better overall survival when receiving surgery.

Conclusion: Our study has provided population-based prognostic analysis in patients with initial bone metastatic breast cancer and constructed a predicting nomogram with good accuracy. The finding of potential benefit of surgery to overall survival will cast some lights on the treatment tactics of this group of patients.

Keywords: de novo stage IV, breast cancer, bone metastase, nomogram, prediction 


\section{INTRODUCTION}

Breast cancer is the most commonly diagnosed malignant tumor and the leading cause of cancer death among females worldwide, accounting for $24.2 \%$ of all new cases and $15.0 \%$ of cases of death (1). Approximately $5-8 \%$ of breast cancer patients demonstrate distant metastasis at first diagnosis (2). De novo stage IV breast cancer is usually considered an incurable disease. The overall 5 -year breast cancer specific survival (BCSS) of de novo stage IV breast cancer patients is about $27 \%$. However, with the advance of systemic therapy and local treatment, the prognosis has been largely improved $(3,4)$.

Metastatic breast cancer (MBC) is a highly heterogeneous disease with a wide range of clinical manifestation from solitary to multiple visceral involvements. Metastatic pattern is highly correlated to breast cancer subtype. Patients with hormone receptor positive and human epidermal growth factor receptor 2 negative $\left(\mathrm{HR}^{+} / \mathrm{HER} 2^{-}\right)$disease were reported to have more bone metastasis, patients with $\mathrm{HR}^{-} / \mathrm{HER} 2^{+}$tumors had more liver metastasis, whereas brain and lung metastasis were more likely to occur in $\mathrm{HR}^{-} / \mathrm{HER} 2^{-}$patients $(5,6)$. Bone metastases, whether oligometastatic or combined with metastasis to other sites, were most commonly diagnosed, representing around $70 \%$ in $\mathrm{MBC}$ patients $(7,8)$. Patients with bone metastasis exhibited preferred prognosis compared with visceral metastasis due to different metastatic pattern of different subtypes $(6,9)$. Even though, different subtypes and metastatic patterns presented divergent outcomes. Previous analysis showed that patients of bone-only metastasis and $\mathrm{HR}^{+} / \mathrm{HER} 2^{-}$subtype better overall survival (OS) $(10,11)$.

Therapeutic goals in MBC are usually maintenance of quality of life and palliation of symptoms. Generally, systemic therapy is the primary choice including chemotherapy, targeted therapy, endocrine therapy and immune therapy. It is still controversial about the role of surgery in metastatic patients. Therefore, surgery for $\mathrm{MBC}$ patients is a choice but not a preference for now with the existing evidence. Subgroup analyses of several retrospective trials have suggested a prolonged survival time for bone metastatic patients, while others turned out just the opposite.

The purpose of our study was to investigate the prognostic factors of de novo stage IV breast cancer patients with bone metastasis and if surgery of the primary site could benefit them.

\section{PATIENTS AND METHODS}

\section{Data Collection}

The data were extracted from the SEER database. Patients diagnosed of breast cancer with de novo bone metastasis from 2010 to 2015 with active follow-up, valid survival time, known subtype information, known American Joint Committee on Cancer (AJCC) system stage, de novo bone involvement, known visceral metastatic status, known surgery of the primary site, known cause of death were included. Patients with other malignant comorbidities were excluded to eliminate the effect of other malignancy to OS. Occult breast cancer patients (T0), undefined $\mathrm{T}$ and $\mathrm{N}$ stage patients were excluded from the analysis. Patients diagnosed only in autopsy and death certification were also excluded. At last, 6,860 patients were included in the analysis.

Before initiating this study, we submitted a data-use agreement to the SEER program and were officially granted access to the database. The variables extracted were age at diagnosis ( $<60$ and $\geq 60$ years old), race (white, black, other >and unknown), gender (female and male), year of diagnosis $(2010,2011,2012,2013$, 2014, 2015), breast subtypes $\left(\mathrm{HR}^{+} / \mathrm{HER} 2^{-}, \mathrm{HR}^{+} / \mathrm{HER}^{+}, \mathrm{HR}^{-} /\right.$ $\mathrm{HER}^{+}{ }^{+}$and $\mathrm{HR}^{-} / \mathrm{HER}^{-}$subtypes), grade (I, II, III, IV, unknown), derived American Joint Committee on Cancer (AJCC) T stage (T1, T2, T3, T4), derived AJCC N stage (N0, N1, N2, N3), marital status at diagnosis (married, unmarried and unknown), insurance status (insured, uninsured and unknown), brain metastasis status at diagnosis (yes or no), liver metastasis status at diagnosis (yes or no), lung metastasis status at diagnosis (yes or no), SEER causespecific death classification (alive or dead of other cause and dead attributable to this cancer), vital status (alive and dead), survival time and surgery information of primary site.

\section{Statistical Analysis}

The frequency and proportion of the baseline characteristics in the study cohort were by described by chi-square test. OS and BCSS were both calculated to evaluate prognosis. Univariate analysis was performed with variables including age, sex, race, grade, subtype, T stage, $\mathrm{N}$ stage, marital status, insurance status, visceral metastases and surgery or not. The statistically meaningful $(\mathrm{p}<0.05)$ variables were taken into the multivariable Cox analysis to determine the independent prognostic factors of patients with bone involvement. Kaplan-Meier survival curves were plotted to estimate the OS and BCSS. Log-rank test was applied in comparing survival. A nomogram model based on the statistically significant factors in multivariate analysis was plotted to predict a patient of specific characteristic. A concordance index (c-index) was calculated to evaluate the performance of the nomogram. Calibration curves were plotted to evaluate the consistency between predicted and actual overall survival at 3 and 5 years, respectively. The cutoff values were generated by X-tile software (3.6.1; https://medicine.yale.edu/lab/ $\mathrm{rimm} /$ research/software). All statistical analyses were carried out with R software (version 3.6.1; http://www.R-project.org). A twotailed $\mathrm{p}<0.05$ was considered statistical significant.

\section{RESULTS}

\section{Baseline Characteristics}

The demographic and clinical characteristic of de novo metastatic breast cancer patients with bone involvement were shown in Table 1. Among the total cohort, $67.06 \%(4,600 / 6,860)$, $17.38 \%(1,192 / 6,860), 6.52 \%(447 / 6,860), 9.05 \%(621 / 6,860)$ of the patients had $\mathrm{HR}^{+} / \mathrm{HER}^{-}, \mathrm{HR}^{+} / \mathrm{HER}^{+}, \mathrm{HR}^{-} / \mathrm{HER}^{+}, \mathrm{HR}^{-} /$ HER $2^{-}$tumors respectively. Patients with $\mathrm{HR}^{+} / \mathrm{HER} 2^{-}$tumors tended to be older and lymph node-negative. Patients with $\mathrm{HR}^{+}$/ $\mathrm{HER}^{+}{ }^{+}$and $\mathrm{HR}^{-} / \mathrm{HER} 2^{+}$tumors had a higher grade and $\mathrm{T}$ stage. Patients with $\mathrm{HR}^{-} / \mathrm{HER} 2^{+}$tumors had increased incidences of 
TABLE 1 | Demographic and clinical characteristics of de novo IV patients with bone metastasis grouped by subtypes.

\begin{tabular}{|c|c|c|c|c|c|c|}
\hline & $\begin{array}{l}\text { All subtypes } \mathrm{n}(\%) \\
\qquad \mathrm{N}=6860\end{array}$ & $\begin{array}{c}\mathrm{HR}^{+} / \mathrm{HER}^{-} \mathrm{n}(\%) \\
\mathrm{N}=4600\end{array}$ & $\begin{array}{c}\mathrm{HR}^{+} / \mathrm{HER} 2^{+} \mathrm{n}(\%) \\
\mathrm{N}=1192\end{array}$ & $\begin{array}{c}\mathrm{HR}^{-} / \mathrm{HER}^{+} \mathrm{n}(\%) \\
\mathrm{N}=447\end{array}$ & $\begin{array}{c}\text { HR }^{-} / \text {HER2 }^{-} \text {n (\%) } \\
\text { N }=621\end{array}$ & $\mathbf{p}$ \\
\hline \multicolumn{7}{|l|}{ Age, y } \\
\hline$<60$ & $3,454(50.35)$ & $2,136(46.43)$ & 714 (59.90) & 283 (63.31) & 321 (51.69) & \multirow[t]{2}{*}{$<0.001$} \\
\hline$>=60$ & 3,406 (49.65) & $2,464(53.57)$ & $478(40.10)$ & 164 (36.69) & 300 (48.31) & \\
\hline \multicolumn{7}{|l|}{ Sex } \\
\hline Female & 6,768 (98.66) & 4,534 (98.57) & $1,173(98.41)$ & 445 (99.55) & 616 (99.19) & \multirow[t]{2}{*}{0.177} \\
\hline Male & $92(1.34)$ & $66(1.43)$ & $19(1.59)$ & $2(0.45)$ & $5(0.81)$ & \\
\hline \multicolumn{7}{|l|}{ Race } \\
\hline White & $5,178(75.61)$ & $3,550(77.17)$ & $888(74.50)$ & $321(71.81)$ & 428 (68.92) & \multirow[t]{4}{*}{$<0.001$} \\
\hline Black & 1,127 (16.43) & $681(14.80)$ & 207 (17.37) & $81(18.12)$ & $158(25.44)$ & \\
\hline Other ${ }^{(1)}$ & $532(7.76)$ & $358(7.78)$ & $96(8.05)$ & $44(9.84)$ & $34(5.48)$ & \\
\hline Unknown & $14(0.20)$ & $11(0.24)$ & $1(0.08)$ & $1(0.22)$ & $1(0.16)$ & \\
\hline \multicolumn{7}{|c|}{ Histologic grade } \\
\hline 1 & 508 (7.41) & 472 (10.26) & $24(2.01)$ & $3(0.67)$ & $9(1.45)$ & \multirow[t]{5}{*}{$<0.001$} \\
\hline$\|$ & $2,761(40.25)$ & $2,121(46.17)$ & 430 (36.07) & $100(22.37)$ & 107 (17.23) & \\
\hline III & 2,603 (37.94) & 1,320 (28.70) & 576 (48.32) & $276(61.74)$ & $431(69.40)$ & \\
\hline$I^{(2)}$ & $24(0.35)$ & $13(0.28)$ & $1(0.08)$ & $2(0.45)$ & $8(1.29)$ & \\
\hline Unknown & $964(14.05)$ & 671 (14.59) & $161(13.51)$ & $66(14.77)$ & 66 (10.63) & \\
\hline \multicolumn{7}{|c|}{ AJCC T stage } \\
\hline 1 & 844 (12.30) & $598(13)$ & 138 (11.58) & 44 (9.84) & 64 (10.31) & \multirow[t]{4}{*}{$<0.001$} \\
\hline 2 & 2,345 (34.18) & 1,647 (35.80) & 397 (33.31) & $118(26.40)$ & $183(29.47)$ & \\
\hline 3 & $1,276(18.60)$ & 868 (18.87) & 206 (17.28) & 85 (19.02) & 117 (18.84) & \\
\hline 4 & 2,395 (34.91) & 1,487 (32.33) & $451(37.84)$ & $200(44.74)$ & 257 (41.38) & \\
\hline \multicolumn{7}{|c|}{ AJCC N stage } \\
\hline 0 & $1,486(21.66)$ & 1,067 (23.20) & 233 (19.55) & 64 (14.32) & 122 (19.65) & \multirow[t]{4}{*}{$<0.001$} \\
\hline 1 & 3,356 (48.92) & $2,220(48.26)$ & $601(50.42)$ & $233(52.13)$ & $302(48.63)$ & \\
\hline 2 & $929(13.54)$ & $642(13.96)$ & $151(12.67)$ & $61(13.65)$ & 75 (12.08) & \\
\hline 3 & 1,089 (15.87) & $671(14.59)$ & 207 (17.37) & 89 (19.91) & $122(19.65)$ & \\
\hline \multicolumn{7}{|c|}{ Marital status } \\
\hline Married & 3135 (45.70) & 2096(45.57) & $548(45.97)$ & 219(48.99) & 272(43.80) & \multirow[t]{3}{*}{0.268} \\
\hline Unmarried $^{(\mathbf{3})}$ & 3386(49.36) & 2276(49.48) & $578(48.49)$ & $205(45.86)$ & $327(52.66)$ & \\
\hline Unknown & 339(4.94) & 228(4.96) & $66(5.54)$ & 23(5.15) & $22(3.54)$ & \\
\hline \multicolumn{7}{|c|}{ Insurance status } \\
\hline Insured ${ }^{(4)}$ & $6,488(94.58)$ & $4,361(94.80)$ & 1113 (93.37) & 425 (95.08) & 589 (94.85) & \multirow[t]{3}{*}{0.625} \\
\hline Uninsured & 269 (3.92) & 171 (3.72) & $58(4.87)$ & $16(3.58)$ & 24 (3.86) & \\
\hline Unknown & $103(1.50)$ & $68(1.48)$ & $21(1.76)$ & $6(1.34)$ & 8 (1.29) & \\
\hline \multicolumn{7}{|c|}{ Brain involvement } \\
\hline No & 6,420 (93.59) & 4,372 (95.04) & 1,097 (92.03) & 395 (88.37) & $556(89.53)$ & \multirow[t]{2}{*}{$<0.001$} \\
\hline Yes & $440(6.41)$ & $228(4.96)$ & $95(7.97)$ & 52 (11.63) & $65(10.47)$ & \\
\hline \multicolumn{7}{|c|}{ Liver involvement } \\
\hline No & 5,356 (78.08) & 3,867 (84.07) & 808 (67.79) & $245(54.81)$ & $436(70.21)$ & \multirow[t]{2}{*}{$<0.001$} \\
\hline Yes & $1,504(21.92)$ & 733 (15.93) & $384(32.21)$ & 202 (45.19) & 185 (29.79) & \\
\hline \multicolumn{7}{|c|}{ Lung involvement } \\
\hline No & $5,162(75.25)$ & $3,544(77.04)$ & 873 (73.24) & 307 (68.68) & 438 (70.53) & \multirow[t]{2}{*}{$<0.001$} \\
\hline Yes & $1,698(24.75)$ & 1,056 (22.96) & 319 (26.76) & 140 (31.32) & $183(29.47)$ & \\
\hline Surgery & & & & & & \\
\hline No & $4,611(67.22)$ & $3,122(67.87)$ & 810 (67.95) & 292 (65.32) & 387 (62.32) & 0.034 \\
\hline Yes & 2,249 (32.78) & $1,478(32.13)$ & 382 (32.05) & 155 (34.68) & 234 (37.68) & \\
\hline
\end{tabular}

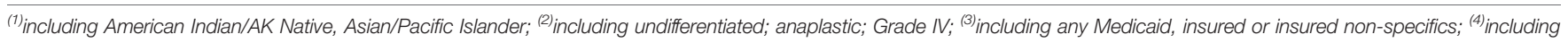
divorced, single (never married), unmarried or domestic partner, widowed and separated.

HR, hormone receptor; HER2, human epidermal growth factor 2; AJCC, American Joint Committee on Cancer.

brain metastases $\left(\mathrm{HR}^{+} / \mathrm{HER} 2^{-}\right.$vs $\mathrm{HR}^{+} / \mathrm{HER}^{+}{ }^{+}$vs $^{-} \mathrm{HR}^{-} / \mathrm{HER}^{+}{ }^{+}$vs $\mathrm{HR}^{-} / \mathrm{HER}^{-}: 4.96$ vs $7.97 \%$ vs 11.63 vs $10.47 \%, \mathrm{p}<0.001$ ), liver metastases $\left(\mathrm{HR}^{+} / \mathrm{HER}^{-}{ }^{-}\right.$vs $\mathrm{HR}^{+} / \mathrm{HER}^{+}{ }^{+}$vs $\mathrm{HR}^{-} / \mathrm{HER}^{+}{ }^{+}$vs $\mathrm{HR}^{-} /$ HER $2^{-}$: 15.93 vs $32.21 \%$ vs 45.19 vs $\left.29.79 \%, \mathrm{p}<0.001\right)$ and lung metastases $\left(\mathrm{HR}^{+} / \mathrm{HER}^{-}{ }^{-}\right.$vs $\mathrm{HR}^{+} / \mathrm{HER}^{+}{ }^{+}$vs $^{-} \mathrm{HR}^{-} / \mathrm{HER}^{+}{ }^{+}$vs $\mathrm{HR}^{-} /$ HER2 $^{-}: 22.96$ vs $26.76 \%$ vs 31.32 vs $29.47 \%$, p $<0.001$ ).

In $\mathrm{HR}^{+} / \mathrm{HER} 2^{-}$subgroup, lung was the most susceptible organ in initial bone involved patients, while in $\mathrm{HR}^{+} / \mathrm{HER}^{+}$, $\mathrm{HR}^{-} / \mathrm{HER}^{+}{ }^{+}$and $\mathrm{HR}^{-} / \mathrm{HER}^{-}$subgroups, concurrent liver involvement was the most common.

\section{Univariable and Multivariable Analysis}

In univariate analysis, we found that patients of older age, black race, higher grade tumors, $\mathrm{HR}^{-} / \mathrm{HER}^{-}$subtype, high $\mathrm{T}$ stage $(\mathrm{T}>2)$, unmarried status, uninsured status, visceral involvement (brain, liver or lung), no primary tumor surgery displayed worse OS (Table 2).

These statistically significant factors were included in the multivariate analysis. Patients older than 60 years old $(\mathrm{HR}=1.43$, $95 \% \mathrm{CI}=1.33-1.52, \mathrm{p}<0.001)$, black race $(\mathrm{HR}=1.27,95 \% \mathrm{CI}=$ $1.16-1.38, \mathrm{p}<0.001$ ), $\mathrm{T} 3$ stage ( $\mathrm{T} 2$ vs $\mathrm{T} 1: \mathrm{HR}=1.04,95 \%$ 
TABLE 2 | Univariate and multivariate cox progression of OS and BCSS of breast cancer patients with initial bone metastasis.

\begin{tabular}{|c|c|c|c|c|c|c|c|c|}
\hline & \multicolumn{4}{|c|}{ Overall survival } & \multicolumn{4}{|c|}{ Breast cancer-specific survival } \\
\hline & HR (95\% Cl) & $\mathbf{P}$ & HR (95\% Cl) & $\mathbf{P}$ & HR (95\% Cl) & $\mathbf{P}$ & HR (95\% Cl) & $\mathbf{P}$ \\
\hline \multicolumn{9}{|l|}{ Age } \\
\hline$<60$ & \multicolumn{4}{|c|}{ Reference } & \multicolumn{4}{|c|}{ Reference } \\
\hline$\geq 60$ & $1.40(1.31-1.49)$ & $<0.001$ & $1.43(1.33-1.52)$ & $<0.001$ & $1.32(1.24-1.41)$ & $<0.001$ & $1.36(1.27-1.45)$ & $<0.001$ \\
\hline Female & \multicolumn{4}{|c|}{ Reference } & \multicolumn{4}{|c|}{ Reference } \\
\hline Male & $1.15(0.88-1.51)$ & 0.302 & / & / & $1.11(0.83-1.48)$ & 0.479 & / & / \\
\hline \multicolumn{9}{|l|}{ Race } \\
\hline White & \multicolumn{4}{|c|}{ Reference } & \multicolumn{4}{|c|}{ Reference } \\
\hline Black & $1.42(1.31-1.54)$ & $<0.001$ & $1.27(1.16-1.38)$ & $<0.001$ & $1.41(1.29-1.53)$ & $<0.001$ & $1.24(1.13-1.35)$ & $<0.001$ \\
\hline Other & $0.92(1.81-1.04)$ & 0.172 & $0.93(0.82-1.05)$ & 0.244 & $0.95(0.83-1.08)$ & 0.432 & $0.95(0.84-1.09)$ & 0.465 \\
\hline$\|$ & $1.28(1.11-1.48)$ & 0.001 & $1.30(1.12-1.50)$ & $<0.001$ & $1.33(1.14-1.55)$ & $<0.001$ & $1.34(1.14-1.56)$ & $<0.001$ \\
\hline III & $1.81(1.57-2.09)$ & $<0.001$ & $1.75(1.51-2.03)$ & $<0.001$ & $1.95(1.68-2.27)$ & $<0.001$ & $1.86(1.59-2.17)$ & $<0.001$ \\
\hline IV & $4.04(2.62-6.21)$ & $<0.001$ & $2.42(1.57-3.74)$ & $<0.001$ & $4.64(3.01-7.15)$ & $<0.001$ & $2.75(1.78-4.27)$ & $<0.001$ \\
\hline Unknown & $1.72(1.47-2.01)$ & $<0.001$ & $1.42(1.21-1.66)$ & $<0.001$ & $1.81(1.53-2.14)$ & $<0.001$ & $1.49(1.25-1.76)$ & $<0.001$ \\
\hline \multicolumn{9}{|l|}{ Subtype } \\
\hline $\mathrm{HR}$ & \multirow{2}{*}{\multicolumn{4}{|c|}{ Reference }} & & Refer & & \\
\hline +/HER2- & & & & & & & & \\
\hline $\begin{array}{l}\text { HR } \\
\text { +/HER2+ }\end{array}$ & $0.80(0.73-0.88)$ & $<0.001$ & $0.65(0.59-0.72)$ & $<0.001$ & $0.82(0.75-0.91)$ & $<0.001$ & $0.65(0.59-0.72)$ & $<0.001$ \\
\hline $\begin{array}{l}\text { HR-/ } \\
\text { HER2+ }\end{array}$ & $0.98(0.86-1.13)$ & 0.8 & $0.74(0.64-0.86)$ & $<0.001$ & $1.02(0.88-1.17)$ & 0.832 & $0.74(0.64-0.85)$ & $<0.001$ \\
\hline $\begin{array}{l}\text { HR- } / \\
\text { HER2- } \\
\text { T }\end{array}$ & $2.94(2.67-3.23)$ & $<0.001$ & $2.51(2.27-2.78)$ & $<0.001$ & $3.03(2.74-3.34)$ & $<0.001$ & $2.54(2.28-2.82)$ & $<0.001$ \\
\hline 0 & & Refer & & & & Refer & & \\
\hline 1 & $0.97(0.89-1.05)$ & 0.464 & / & / & $0.99(0.91-1.08)$ & 0.829 & / & / \\
\hline 2 & $0.97(0.87-1.08)$ & 0.607 & / & / & $0.98(0.87-1.10)$ & 0.702 & / & / \\
\hline 3 & $1.03(0.93-1.14)$ & 0.618 & / & / & $1.06(0.95-1.18)$ & 0.287 & / & / \\
\hline Marital sta & & & & & & & & \\
\hline Married & & Refer & & & & Refer & & \\
\hline Unmarried & $1.36(1.27-1.45)$ & $<0.001$ & $1.23(1.15-1.32)$ & $<0.001$ & $1.33(1.24-1.42)$ & $<0.001$ & $1.21(1.13-1.30)$ & $<0.001$ \\
\hline Unknown & $1.11(0.95-1.30)$ & 0.17 & $1.05(0.90-1.23)$ & 0.546 & $1.14(0.97-1.33)$ & 0.113 & $1.07(0.91-1.26)$ & 0.396 \\
\hline Insurance & & & & & & & & \\
\hline Insured & & Refer & & & & Refer & & \\
\hline Uninsured & $1.27(1.09-1.48)$ & 0.002 & $1.20(1.03-1.40)$ & 0.021 & $1.34(1.14-1.56)$ & $<0.001$ & $1.26(1.07-1.47)$ & 0.004 \\
\hline Unknown & $0.96(0.73-1.25)$ & 0.744 & $0.89(0.67-1.17)$ & 0.393 & $0.98(0.75-1.3)$ & 0.902 & $0.90(0.68-1.20)$ & 0.480 \\
\hline Brain invo & & & & & & & & \\
\hline No & & Refer & & & & Refer & & \\
\hline Yes & $2.31(2.07-2.59)$ & $<0.001$ & $1.83(1.63-2.05)$ & $<0.001$ & $2.37(2.12-2.66)$ & $<0.001$ & $1.85(1.64-2.08)$ & $<0.001$ \\
\hline Liver invol & & & & & & & & \\
\hline No & & Refer & & & & Refer & & \\
\hline Yes & $1.83(1.71-1.97)$ & $<0.001$ & $1.68(1.56-1.82)$ & $<0.001$ & $1.93(1.79-2.08)$ & $<0.001$ & $1.75(1.62-1.90)$ & $<0.001$ \\
\hline Lung invol & & & & & & & & \\
\hline
\end{tabular}




\begin{tabular}{|c|c|c|c|c|c|c|c|c|}
\hline & \multicolumn{4}{|c|}{ Overall survival } & \multicolumn{4}{|c|}{ Breast cancer-specific survival } \\
\hline & \multicolumn{2}{|c|}{ Univariate analysis } & \multicolumn{2}{|c|}{ Multivariate analysis } & \multicolumn{2}{|c|}{ Univariate analysis } & \multicolumn{2}{|c|}{ Multivariate analysis } \\
\hline & HR (95\% Cl) & $\mathbf{P}$ & HR (95\% Cl) & $\mathbf{P}$ & $\mathrm{HR}(95 \% \mathrm{Cl})$ & $\mathbf{P}$ & HR (95\% Cl) & $\mathbf{P}$ \\
\hline No & \multicolumn{4}{|c|}{ Reference } & \multicolumn{4}{|c|}{ Reference } \\
\hline Yes & $1.60(1.5-1.72)$ & $<0.001$ & $1.22(1.14-1.32)$ & $<0.001$ & $1.62(1.50-1.74)$ & $<0.001$ & $1.22(1.13-1.32)$ & $<0.001$ \\
\hline \multicolumn{9}{|c|}{ Surgery } \\
\hline No & \multicolumn{4}{|c|}{ Reference } & \multicolumn{4}{|c|}{ Reference } \\
\hline Yes & $0.56(0.5-0.60)$ & $<0.001$ & $0.60(0.56-0.65)$ & $<0.001$ & $0.56(0.52-0.60)$ & $<0.001$ & $0.60(0.56-0.65)$ & $<0.001$ \\
\hline
\end{tabular}

HR, hormone receptor; HER2, human epidermal growth factor 2; AJCC, American Joint Committee on Cancer; Cl, confidence interval.

$\mathrm{CI}=0.93-1.16, \mathrm{p}=0.527 ; \mathrm{T} 3$ vs $\mathrm{T} 1: \mathrm{HR}=1.19,95 \% \mathrm{CI}=1.05-$ $1.34, \mathrm{p}=0.005)$ were significantly related to worse OS. Compared with $\mathrm{HR}^{+} / \mathrm{HER}^{-}$patients, $\mathrm{HR}^{+} / \mathrm{HER} 2^{+}$and $\mathrm{HR}^{-} / \mathrm{HER} 2^{+}$ subtype showed improved OS $\left(\mathrm{HR}^{+} / \mathrm{HER}^{+}\right.$: $\mathrm{HR}=0.65,95 \%$ $\mathrm{CI}=0.59-0.72, \mathrm{p}<0.001 ; \mathrm{HR}^{-} / \mathrm{HER}^{+}: \mathrm{HR}=0.74,95 \% \mathrm{CI}=$ 0.64-0.86, $\mathrm{p}<0.001)$, while $\mathrm{HR}^{-} / \mathrm{HER} 2^{-}$subtype demonstrated the worst outcome $(\mathrm{HR}=2.51,95 \% \mathrm{CI}=2.27-2.78, \mathrm{p}<0.001)$. Social factors like marital status $(\mathrm{HR}=1.23,95 \% \mathrm{CI}=1.15-1.32$, $\mathrm{p}<0.001)$ and insurance status $(\mathrm{HR}=1.2,95 \% \mathrm{CI}=1.03-1.4$, $\mathrm{p}<0.001)$ were also associated with OS.

Among the 6,860 patients with bone metastatic lesions, 4096 cases $(59.71 \%)$ demonstrated bone-only metastasis and 2,764 cases $(40.29 \%)$ displayed concurrent visceral metastases. The outcome was much worse when combining visceral metastases (BOM vs bone and brain metastasis: median OS $=43$ vs 17 months, $\mathrm{HR}=1.83,95 \% \mathrm{CI}=1.63-2.05, \mathrm{p}<0.001$; $\mathrm{BOM}$ vs bone and liver metastasis: median $\mathrm{OS}=43$ vs 27 months, $\mathrm{HR}=1.68$,
95\% CI $=1.56-1.82, \mathrm{p}<0.001 ; \mathrm{BOM}$ vs bone and lung metastasis is: median $\mathrm{OS}=43$ vs 31 months, $\mathrm{HR}=1.22,95 \% \mathrm{CI}=1.14-1.32$, $\mathrm{p}<0.001)$. In terms of BCSS, univariate and multivariate results identified the same prognostic factors as OS (Table 2).

\section{Development and Validation of a 3-Year and 5-Year OS Predicting Nomogram}

On the basis of factors independently associated with OS and BCSS, a nomogram, including age, grade, race, subtype, $\mathrm{T}$ stage, marital status, insurance status and visceral involvement, was developed to predict a 3-year and 5-year OS. A total nomogram score was generated for a specific patient, which was corresponded to a predicted 3- and 5-year survival (Figure 1). The nomogram showed medium accuracy in predicting the OS, with a C-index of $0.66(95 \% \mathrm{CI}=0.65-0.67)$. The calibration curves suggested that the predictive outcome have good accordance with the actual 3- and 5-year OS (Figure 2).

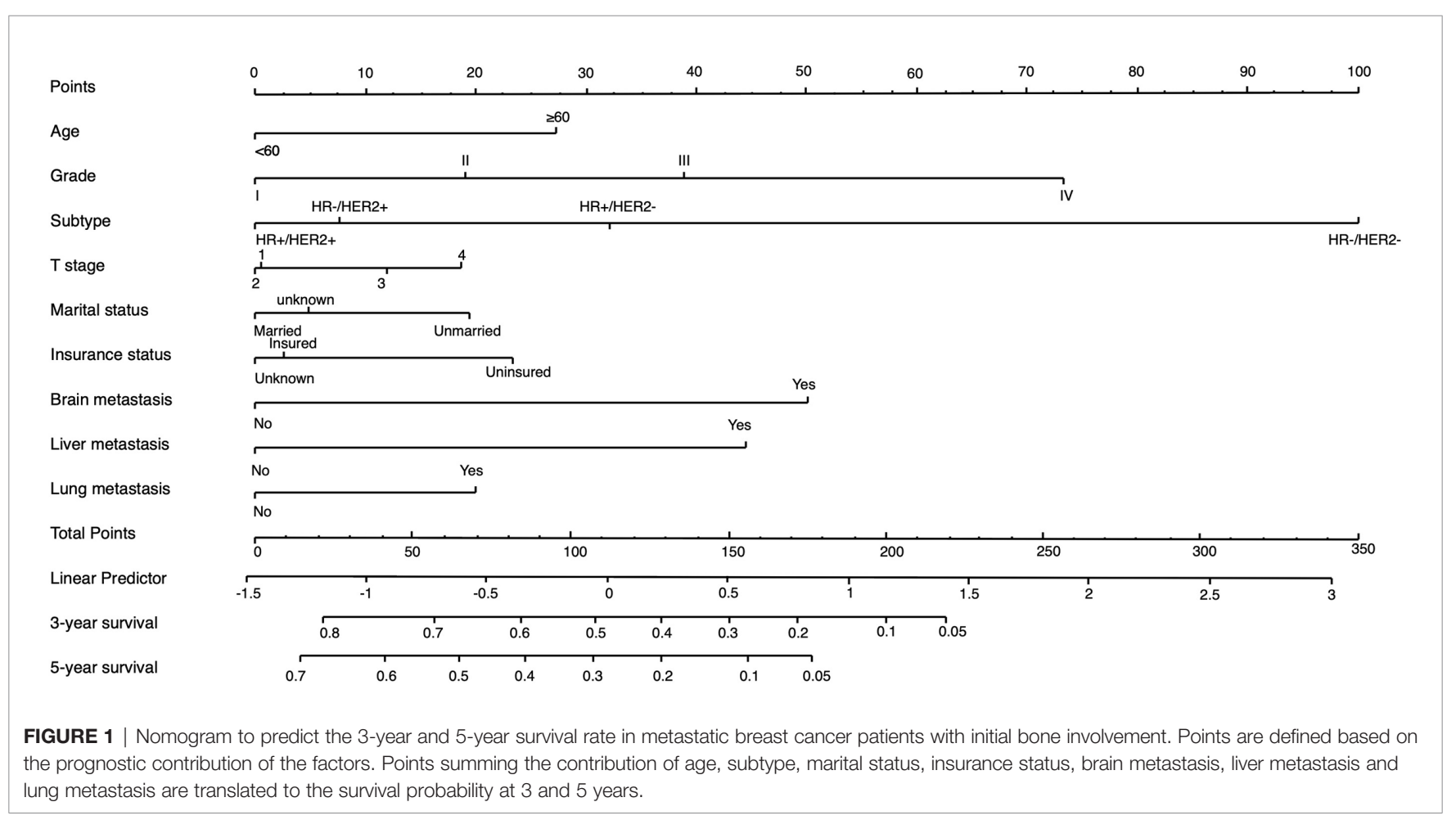


A

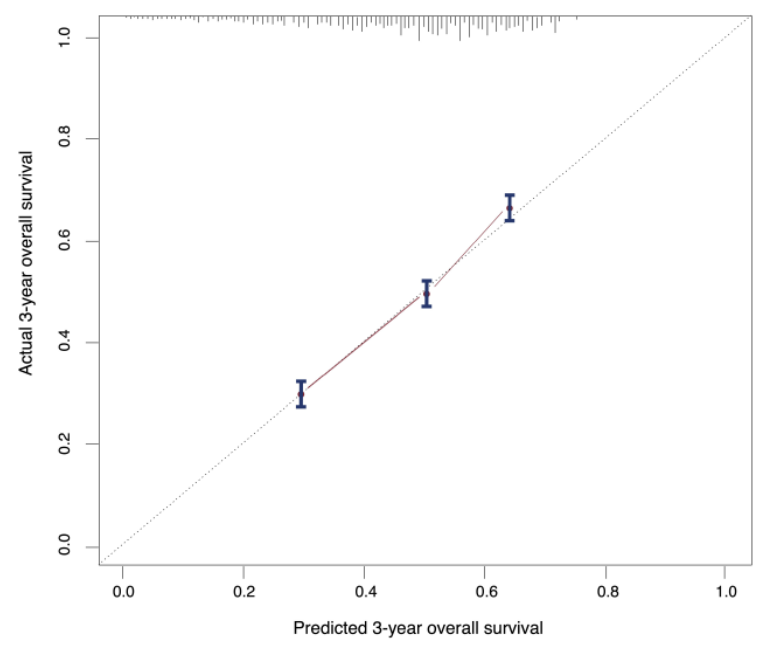

B

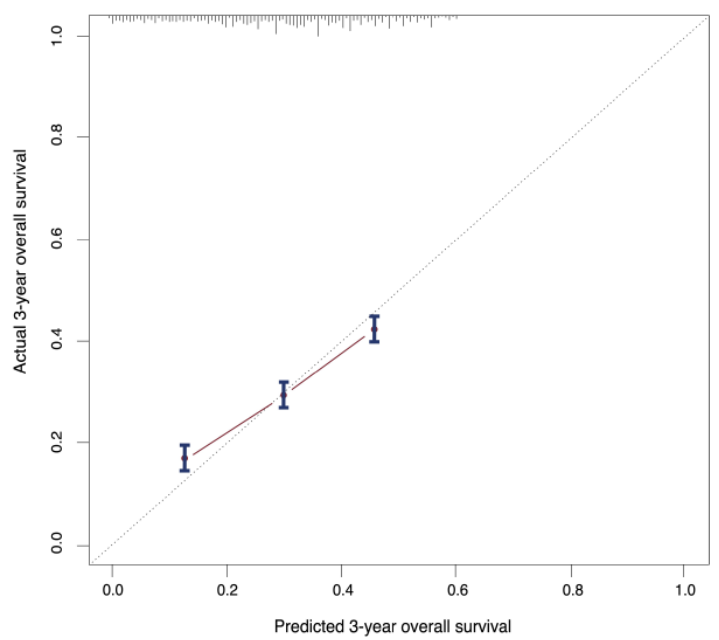

FIGURE 2 | Calibration curves compare predicted and actual (A) 3-year and (B) 5-year overall survival rates. Probability of survival based on the nomogram is listed on the $\mathrm{x}$-axis, while the actual probability of survival is listed on the $y$-axis. The calibration curves suggested that the predictive outcome have good accordance with the actual 3- and 5-year OS.

When calculated as a continuous variable, a higher nomogram score was related to a worse OS (HR $=1.01,95 \%$ $\mathrm{CI}=1.01-1.01, \mathrm{p}<0.05)$. According to the cutoff values provided by $\mathrm{X}$-tile, a risk stratification model was also generated. All the patients were divided into three groups: low-risk patients $(3,092,45.07 \%$, total points $<=86)$, intermediate-risk patients $(2,976,43.38 \%$, total points 87 $156)$, high-risk patients $(792,12.55 \%$, total points $>=157)$. The median OS of three groups were 49 months $(95 \% \mathrm{CI}=$ 47-53), 29 months $(95 \% \mathrm{CI}=28-31)$ and 11 months $(95 \% \mathrm{CI}=$ $10-12)$, separately $(\mathrm{p}<0.05)$. The survival curves indicated that the risk stratification could well differentiate OS and BCSS in all subgroups $(\mathrm{p}<0.05)$ (Figure 3).

\section{Benefits of Primary Tumor Surgery in Patients Subdivided by Molecular Subtypes and Metastatic Sites}

In the whole cohort, primary tumor surgery could prolong OS $(\mathrm{HR}=0.56,95 \% \mathrm{CI}=0.52-0.60, \mathrm{p}<0.001)$. In terms of molecular subtypes, surgery provided extra survival benefit in all subtypes $\left(\mathrm{HR}^{+} / \mathrm{HER} 2^{-}: \mathrm{HR}=0.56,95 \% \mathrm{CI}=0.51-0.61, \mathrm{p}<0.001 ; \mathrm{HR}^{+} /\right.$ $\mathrm{HER}^{+}$: HR $0.48,95 \% \mathrm{CI}=0.39-0.58, \mathrm{p}<0.001 ; \mathrm{HR}^{-} / \mathrm{HER}^{+}$: $\mathrm{HR}=0.50,95 \% \mathrm{CI}=0.37-0.66, \mathrm{p}<0.001 ; \mathrm{HR}^{-} / \mathrm{HER}^{-}: \mathrm{HR}=$ $0.50,95 \% \mathrm{CI}=0.41-0.59, \mathrm{p}<0.001$ ) (Figure 4). In terms of metastatic burden, BOM, bone and liver metastasis as well as bone and lung metastasis patients could benefit from surgery (BOM: $\mathrm{HR}=0.57,95 \% \mathrm{CI}=0.52-0.63, \mathrm{p}<0.001$; bone and liver
A

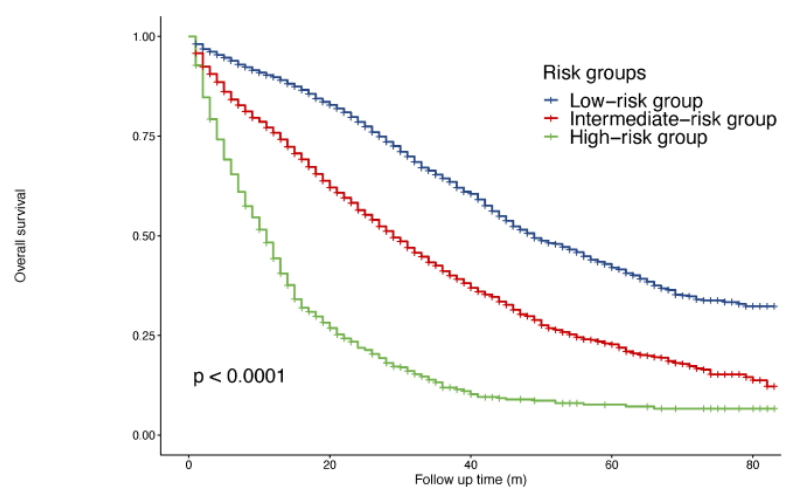

B

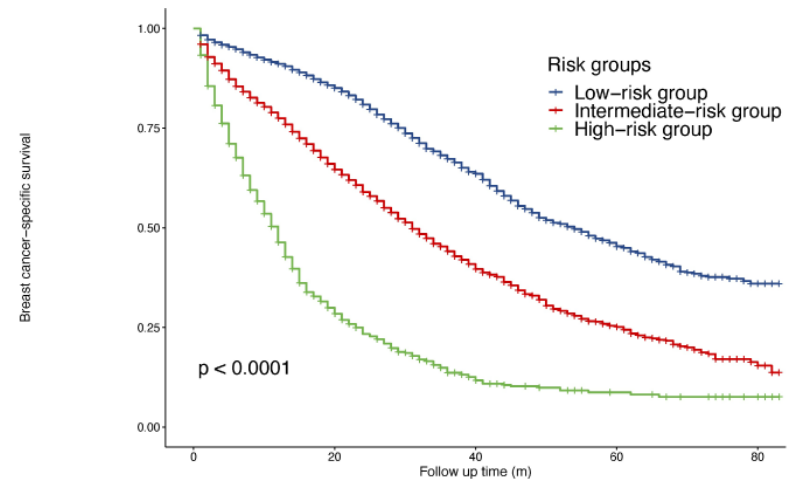

FIGURE 3 | Survival of de novo bone metastatic patients according to different risk groups. (A) OS in nomogram-based low-, intermediate-and high-risk subgroups; (B) BCSS in nomogram-based low-, intermediate-and high-risk subgroups. 
Lit et al.

Prognosis of MBC Patients

A HR+/HER2-

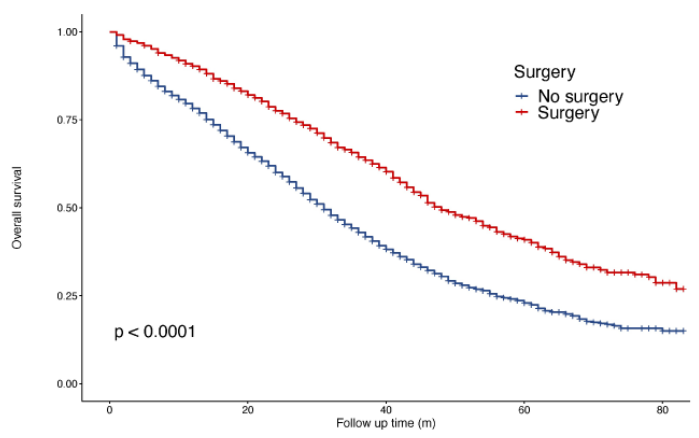

C HR-/HER2+

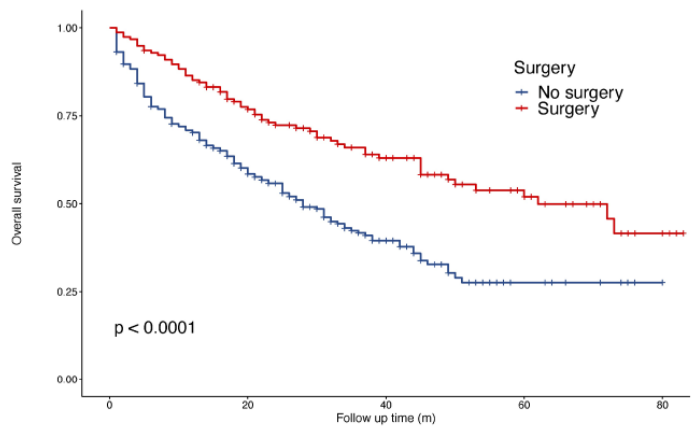

E HR+/HER2-

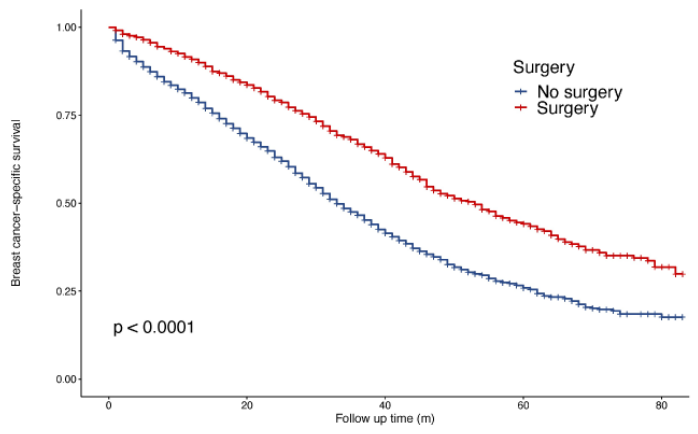

G HR-/HER2+

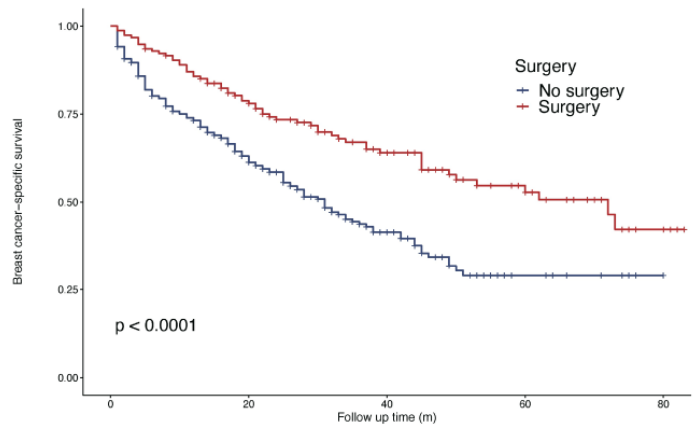

B HR+/HER2+

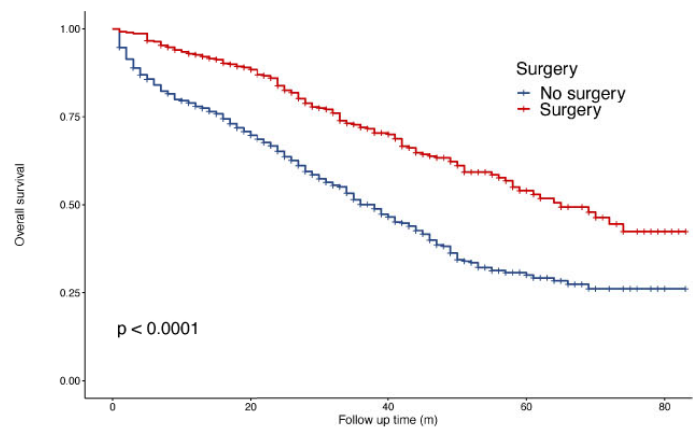

D HR-/HER2-

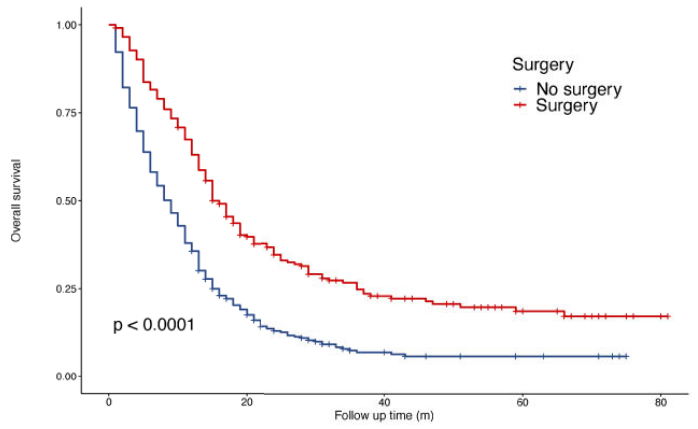

F HR+/HER2+

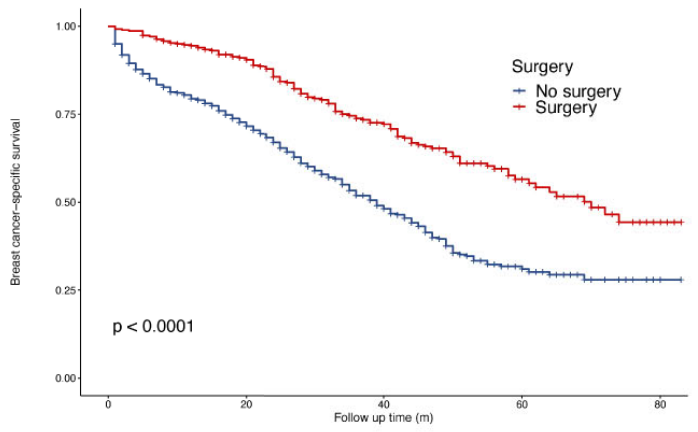

H HR-/HER2-

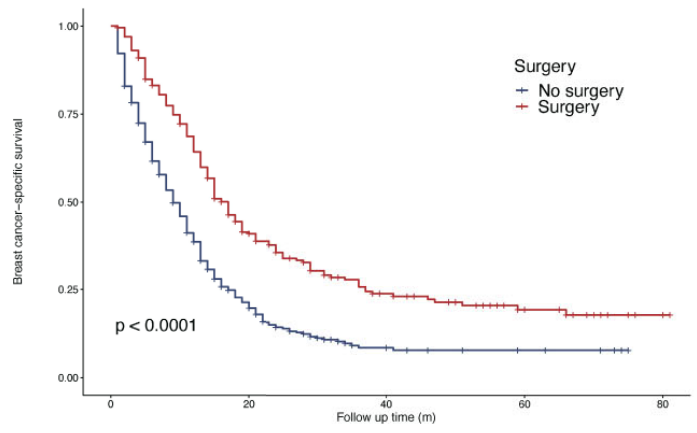

FIGURE 4 | Survival of de nov bone metastatic patients in different subtypes according to primary surgery. (A, E) OS and BCSS in patients with HR ${ }^{+} / \mathrm{HER}^{-}$ tumors; (B, F) OS and BCSS in patients with $\mathrm{HR}^{+} / \mathrm{HER} 2^{+}$tumors; (C, G) OS and BCSS in patients with $\mathrm{HR}^{-} / \mathrm{HER} 2^{+}$tumors; (D, H) OS and BCSS in patients with $\mathrm{HR}^{-} / \mathrm{HER}^{-}$tumors.

Frontiers in Oncology | www.frontiersin.org

7

December 2020 | Volume 10 | Article 580112 
metastasis: $\mathrm{HR}=0.70,95 \% \mathrm{CI}=0.58-0.84, \mathrm{p}<0.001$; bone and lung metastasis: $\mathrm{HR}=0.73,95 \% \mathrm{CI}=0.60-0.88, \mathrm{p}=0.001)$. However, surgery did not significantly benefit patients with bone and brain metastasis $(\mathrm{HR}=0.64,95 \% \mathrm{CI}=0.40-1.02, \mathrm{p}=0.063)$ (Figure 5). Similarly, the analysis of BCSS showed consistent results.

\section{Benefits of Primary Tumor Surgery in Patients Subdivided by Nomogram Risk Category}

The Kaplan-Meier curves showed that surgery of the primary site could prolong OS in all risk subgroups (low-risk group: $\mathrm{HR}=$ $0.53,95 \% \mathrm{CI}=0.47-0.59, \mathrm{p}<0.05$; intermediate-risk group: $\mathrm{HR}=$ $0.66,95 \% \mathrm{CI}=0.59-0.73, \mathrm{p}<0.05$; high-risk group: $\mathrm{HR}=0.69$, $95 \% \mathrm{CI}=0.59-0.82, \mathrm{p}<0.05$ ) (Figure 6). Similar trends were achieved in BCSS.

\section{DISCUSSION}

With huge diversity and heterogeneity, the prognosis and treatment tactics of de novo stage IV breast cancer should be tailored in the light of their clinicopathological features, metastatic burden and even social status. The current study reported the prognosis of this group of patients with bone metastases according to different molecular subtypes as well as potential benefits of surgery of the primary tumor. To our knowledge, this analysis is the first population-based, retrospective, prognostic and predictive survival analysis and the first one to explore the surgical benefits of this group of patients based on subtypes and metastatic burdens. The prognostic nomogram we generalized included all the independent risk factors and show a good accuracy and accordance in predicting the survival rate of each case. The risk stratification model further differentiated patients of distinct risk subgroups, which provides critical information for indicating outcomes and facilitates individualized treatment choices.

In this analysis, several features associated with improved outcome were identified, including $\mathrm{HR}-/ \mathrm{HER} 2^{+}$subtype, age $<60$ years old, white race, lower grade, lower $\mathrm{T}$ stage $(\mathrm{T} \leq \mathrm{T} 2)$, no concurrent visceral metastasis, married and insured status. Patients of HR+/HER2- subtypes usually present preferred prognosis among all subtypes but in our analysis, patients of $\mathrm{HR}^{+} / \mathrm{HER} 2^{+}$subtype $(1,192 / 6,860)$ demonstrated the best outcome among all subtypes in our analysis. Similar results were reported in previous studies involving patients with various sites of metastasis. In a multicenter study held in Netherlands, the $\mathrm{HR}^{+} / \mathrm{HER} 2^{+}$subtype was associated with the longest survival after diagnosis of distant metastasis $\left(\mathrm{HR}^{+} /\right.$ $\mathrm{HER}^{+}$vs $\mathrm{HR}^{+} / \mathrm{HER}^{-}: \mathrm{HR}=0.64,95 \% \mathrm{CI}=0.45-0.92, \mathrm{p}=$ $0.02)$ (12). In another SEER-based analysis, $\mathrm{HR}^{+} / \mathrm{HER} 2^{+}$tumor was reported to have the best prognosis $\left(\mathrm{HR}^{+} / \mathrm{HER}^{+}{ }^{+} \mathrm{vs}^{+} /\right.$ $\mathrm{HER}^{-}$: $\left.\mathrm{HR}=0.85,95 \% \mathrm{CI}=0.77-0.94, \mathrm{p}<0.05\right)$ (13). We postulated that several reasons may contribute to the favorable survival of $\mathrm{HR}^{+} / \mathrm{HER}^{+}$subtype. First of all, different subtypes demonstrated a totally distinguished metastatic pattern. In another SEER-based study, $\mathrm{HR}^{+}$(both HER2 ${ }^{-}$and $\mathrm{HER} 2^{+}$) was significantly associated with an elevated bone metastasis and better prognosis (11). Intrinsic biological characteristics and metastatic propensity of HR-positive subtype mainly contributes the good prognosis. In our subgroup analysis, we found that in different metastatic burdens, most patients with HR-positive tumors have better prognosis than those with HR-negative tumors, except patients with bone and brain metastasis (HR = $0.79,95 \% \mathrm{CI}=0.51-1.24, \mathrm{p}=0.31$ ). Secondly, the development of HER2 targeted therapy has evolved greatly. Trastuzumab, a humanized monoclonal antibody targeting HER2, reduced $44 \%$ of death risk in women with HER2+ disease compared with that of HER2- disease who did not received HER2-targeted therapy in the metastatic setting (14). In CLEOPATRA trial, the addition of pertuzumab to trastuzumab and docetaxel further improved OS in patients with HER2 ${ }^{+} \mathrm{MBC}(\mathrm{HR}=0.66,95 \%$ CI $0.52-0.84$, $\mathrm{p}=0.0008$ ) for first-line treatment (15). In progressed patients, trastuzumab emtansine could improve OS compared with capecitabine and lapatinib for second-line treatment as reported in EMILIA trial ( $\mathrm{HR}=0.75,95 \%$ CI 0.64-0.88) (16). Thirdly, HR-positive breast cancers might display more indolent biological features than HR-negative tumors (17), and options for endocrine therapy have expanded in the last two decades. For postmenopausal patients, aromatase inhibitors (AIs) are recommended first-line endocrine therapy with or without cyclin dependent kinases 4/6 inhibitors. Multi-line endocrine modalities were available after progression or endocrine resistance in metastatic HR-positive breast cancer (18-22). Fourthly, in preclinical researches, the inhibition of HER2 could also improve endocrine sensitivity by crosstalk between HER2 and HR $(23,24)$. In clinical trials, the PERTAIN and ALTERNATIVE trial showed that the combination of HR and HER2 targeting therapy offers an effective and safe regimen $(25,26)$.

Surgery of the primary site of de novo $\mathrm{MBC}$ is a controversial topic with conflicting evidences. Many retrospective analyses of large cohort such as SEER and national cancer database (NCDB) or monocentric database have proven a better outcome of primary surgery in selected patients (5, 27-36). However, retrospective results are usually undermined for selection bias (37). Several prospective trials have also addressed this issue. A multicenter Turkish trial MF07-01 showed a statistically significant improvement in surgery arm in 5-year follow-up, especially in patients with ER/PR (+) or HER2(-) tumor, solitary bone metastasis or younger age ( $<55$ years old) (38). An Indian randomized controlled trial in patients responsive to first-line treatment also showed that surgery could not improve OS (39). However, these prospective trials were also questioned for insufficient chemotherapy, deviation from contemporary practice, insufficient adapted $\mathrm{p}$ value and so on $(27,40,41)$. In spite of these contradictory results, the present study suggested that in well-selected patients, primary surgery might be considered one of the treatment options.

Metastatic burden is another critical factor when making surgical decisions. The current study indicated that apart from patients with bone and brain metastasis, patients of other 
Lir et al.

Prognosis of MBC Patients

A Bone-only metastasis

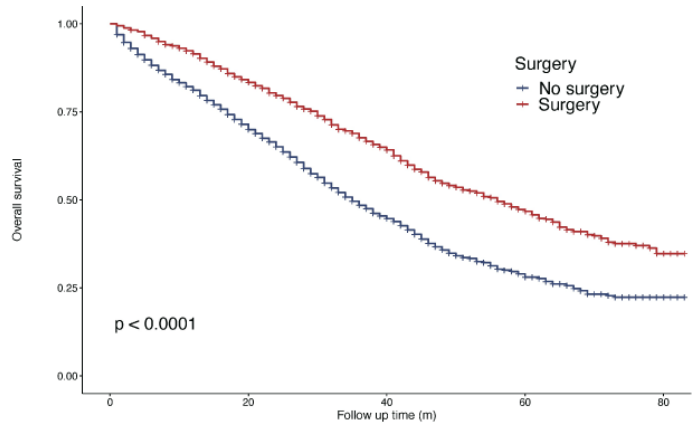

C Bone and liver metastasis

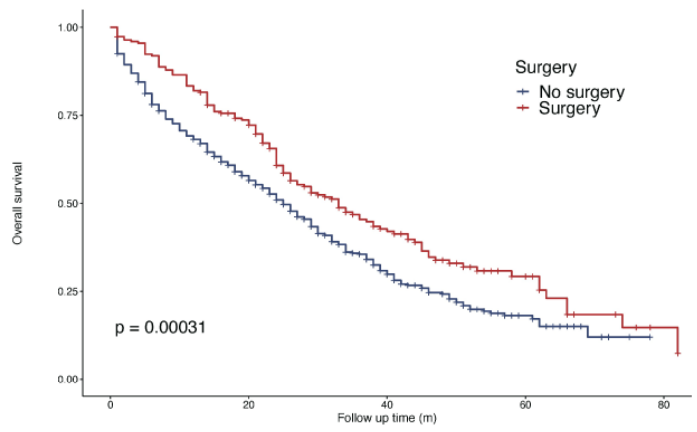

E Bone-only metastasis

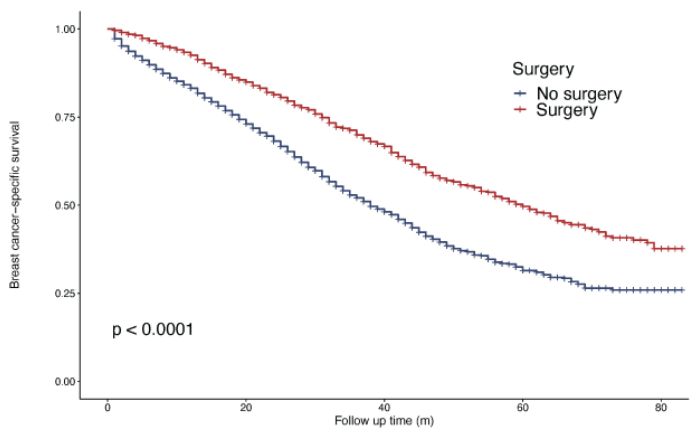

G Bone and liver metastasis

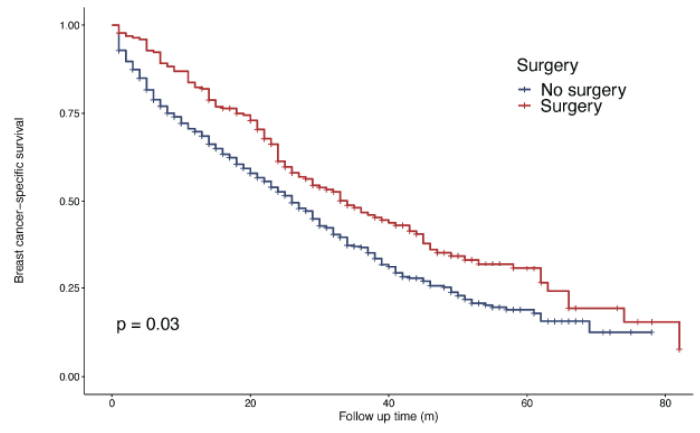

B Bone and brain metastasis

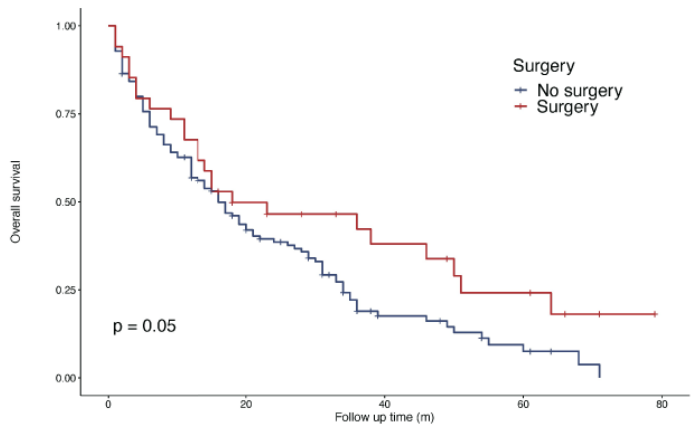

D Bone and lung metastasis

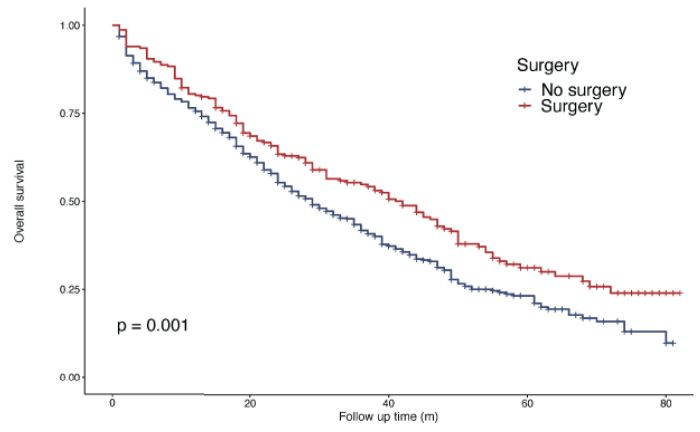

F Bone and brain metastasis

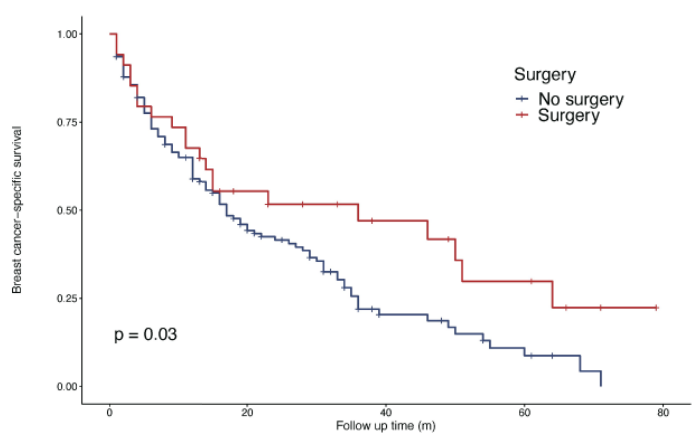

H Bone and lung metastasis

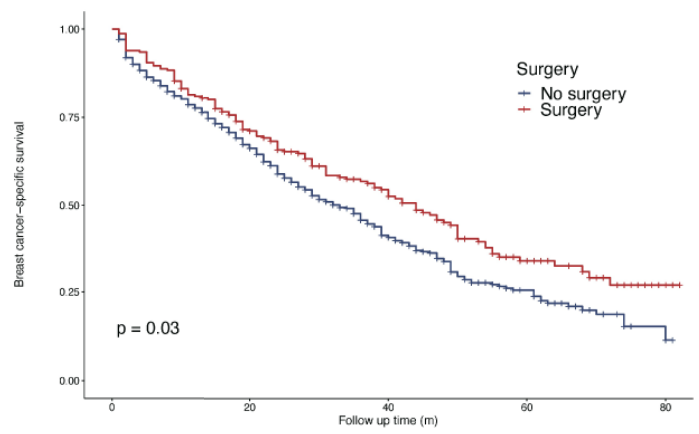

FIGURE 5 | Survival of de nov bone metastatic patients in different metastatic burdens according to primary surgery. (A, E) OS and BCSS in patients with boneonly metastasis; (B, F) OS and BCSS in patients with bone and brain metastasis; (C, G) OS and BCSS in patients with bone and liver metastasis; (D, H) OS and BCSS in patients with bone and lung metastasis.

Frontiers in Oncology | www.frontiersin.org

9

December 2020 | Volume 10 | Article 580112 
A Low-risk group

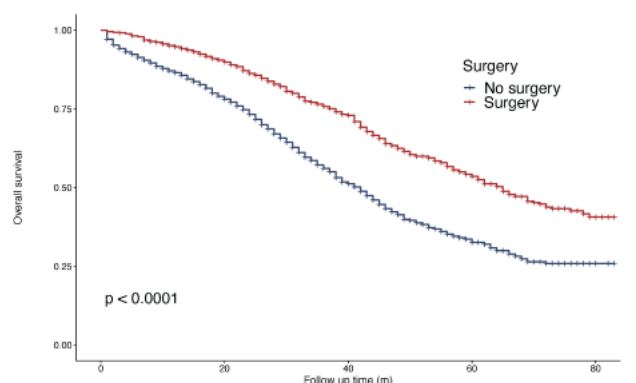

D Low-risk group

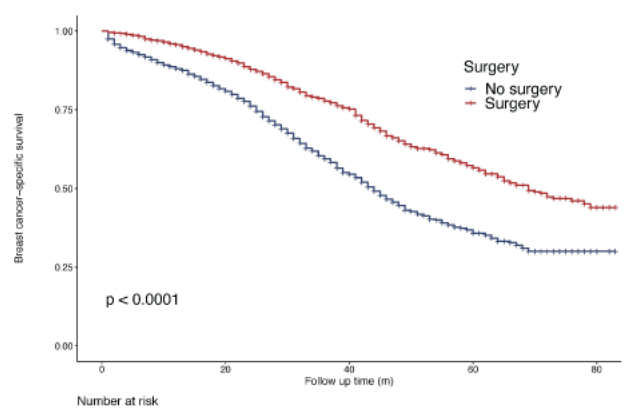

\section{B Intermediate-risk group}

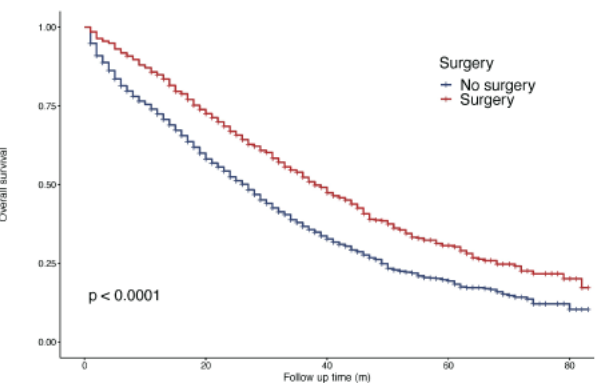

E Intermediate-risk group

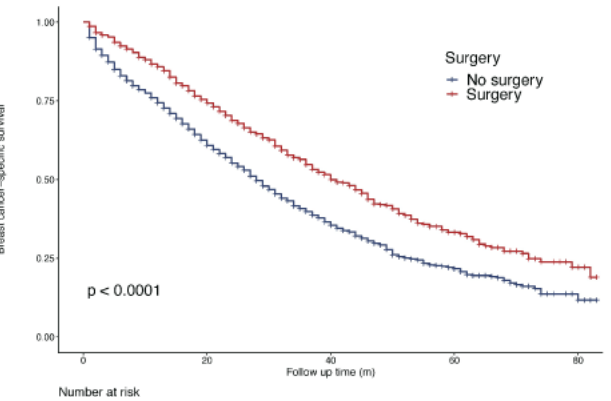

C High-risk group

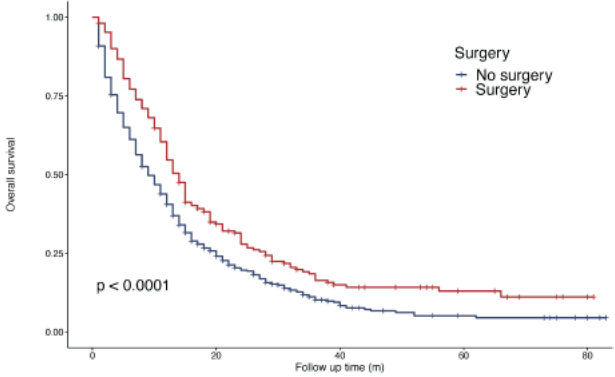

F High-risk group

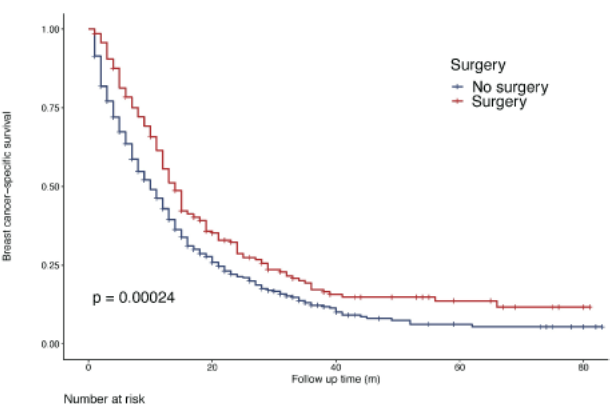

FIGURE 6 | Survival of de novo bone metastatic patients in different nomogram-based risk groups according to primary surgery. (A, D) OS and BCSS in nomogram-based low-risk group; (B, E) OS and BCSS in nomogram-based intermediate-risk group; (C, F) OS and BCSS in nomogram-based high-risk group. 
metastatic patterns might benefit from surgery. Likewise in a subdivision analysis of $\mathrm{M} 1$ patients, preferred prognosis was seen across all subdivisions after surgery except M1c category which is defined as brain involvement or multiple visceral metastasis (42). When it comes to molecular subtype, previous studies showed less benefit of surgery in metastatic triple-negative breast cancer (TNBC) patients. However, patients with bone metastatic TNBC in our cohort exhibited improved survival after primary surgery. Previous study in well-selected and risk-stratified patients demonstrated similar results in TNBC tumors (43). In summary, $\mathrm{MBC}$ is no more a contradiction to primary surgery, specified risk-subdivision should be employed to better screen appropriate patients for customized therapy to bring along maximum benefit.

There are some limitations of this research though. The SEER database covers about $30 \%$ of the USA population, which offers a highly representation of a general situation but on the other hand, makes it immature to apply in Asian and Chinese population on the basis of ethnic differences. In SEER database, significant confounding prognostic factors like complications, detailed treatments, treatment sequence, treatment duration, margin status, recurrence score cannot be attained, which will greatly affect the applicability of the study in real-world cases. Even though the nomogram achieved acceptable prediction and risk stratification efficacy, it lacked external validation to further enforce the reliability. The result of our analysis should be interpreted with caution and applied in well-selected cases.

In conclusion, the current study identified potential prognostic factors in predicting survival in patients with de novo MBC with

\section{REFERENCES}

1. Bray F, Ferlay J, Soerjomataram I, Siegel RL, Torre LA, Jemal A. Global Cancer Statistics 2018: GLOBOCAN Estimates of Incidence and Mortality Worldwide for 36 Cancers in 185 Countries. CA Cancer J Clin (2018) 68:394424. doi: $10.3322 / \mathrm{caac} .21492$

2. DeSantis CE, Ma J, Gaudet MM, Newman LA, Miller KD, Goding Sauer A, et al. Breast cancer statistics, 2019. CA Cancer J Clin (2019) 69(6):438-51. doi: $10.3322 /$ caac. 21583

3. Arnedos M, Vicier C, Loi S, Lefebvre C, Michiels S, Bonnefoi H, et al. Precision medicine for metastatic breast cancer-limitations and solutions. Nat Rev Clin Oncol (2015) 12(12):693-704. doi: 10.1038/nrclinonc.2015.123

4. Harbeck N, Gnant M. Breast cancer. Lancet (2017) 389(10074):1134-50. doi: 10.1016/S0140-6736(16)31891-8

5. Gong Y, Liu YR, Ji P, Hu X, Shao ZM. Impact of molecular subtypes on metastatic breast cancer patients: a SEER population-based study. Sci Rep (2017) 7:45411. doi: 10.1038/srep45411

6. Gerratana L, Fanotto V, Bonotto M, Bolzonello S, Minisini AM, Fasola G, et al. Pattern of metastasis and outcome in patients with breast cancer. Clin Exp Metastasis (2015) 32(2):125-33. doi: 10.1007/s10585-015-9697-2

7. Coleman RE. Clinical features of metastatic bone disease and risk of skeletal morbidity. Clin Cancer Res (2006) 12(20 Pt 2):6243s-9s. doi: 10.1158/10780432.CCR-06-0931

8. Kuchuk I, Hutton B, Moretto P, Ng T, Addison CL, Clemons M. Incidence, consequences and treatment of bone metastases in breast cancer patientsExperience from a single cancer centre. J Bone Oncol (2013) 2(4):137-44. doi: 10.1016/j.jbo.2013.09.001

9. Ording AG, Heide-Jorgensen U, Christiansen CF, Norgaard M, Acquavella J, Sorensen HT. Site of metastasis and breast cancer mortality: a Danish bone metastasis and suggested primary surgery might increase survival in selected subgroup of patients. The nomogram we constructed provided a quantitative method to predict survival of individuals and well differentiated patients of different risk subgroups.

\section{DATA AVAILABILITY STATEMENT}

Publicly available datasets were analyzed in this study. This data can be found here: Surveillance, Epidemiology, and End Results (SEER) database (https://seer.cancer.gov/).

\section{AUTHOR CONTRIBUTIONS}

DL and JW contributed equally to the study design, data collection, statistical analysis and manuscript writing. LZ conceptualized the study and was involved in result interpretation and manuscript writing. CL, LA, and SD helped with data collection. All authors contributed to the article and approved the submitted version.

\section{SUPPLEMENTARY MATERIAL}

The Supplementary Material for this article can be found online at: https://www.frontiersin.org/articles/10.3389/fonc.2020. 580112/full\#supplementary-material nationwide registry-based cohort study. Clin Exp Metastasis (2017) 34 (1):93-101. doi: 10.1007/s10585-016-9824-8

10. Schroder J, Fietz T, Kohler A, Petersen V, Tesch H, Spring L, et al. Treatment and pattern of bone metastases in 1094 patients with advanced breast cancer Results from the prospective German Tumour Registry Breast Cancer cohort study. Eur J Cancer (2017) 79:139-48. doi: 10.1016/j.ejca.2017.03.031

11. Xiong Z, Deng G, Huang X, Li X, Xie X, Wang J, et al. Bone metastasis pattern in initial metastatic breast cancer: a population-based study. Cancer Manag Res (2018) 10:287-95. doi: 10.2147/CMAR.S155524

12. Lobbezoo DJ, van Kampen RJ, Voogd AC, Dercksen MW, van den Berkmortel F, Smilde TJ, et al. Prognosis of metastatic breast cancer subtypes: the hormone receptor/HER2-positive subtype is associated with the most favorable outcome. Breast Cancer Res Treat (2013) 141(3):507-14. doi: 10.1007/s10549-013-2711-y

13. Xiao W, Zheng S, Yang A, Zhang X, Zou Y, Tang H, et al. Breast cancer subtypes and the risk of distant metastasis at initial diagnosis: a populationbased study. Cancer Manag Res (2018) 10:5329-38. doi: 10.2147/ CMAR.S176763

14. Dawood S, Broglio K, Buzdar AU, Hortobagyi GN, Giordano SH. Prognosis of women with metastatic breast cancer by HER2 status and trastuzumab treatment: an institutional-based review. J Clin Oncol (2010) 28(1):92-8. doi: 10.1200/JCO.2008.19.9844

15. Swain SM, Kim S-B, Cortés J, Ro J, Semiglazov V, Campone M, et al. Pertuzumab, trastuzumab, and docetaxel for HER2-positive metastatic breast cancer (CLEOPATRA study): overall survival results from a randomised, double-blind, placebo-controlled, phase 3 study. Lancet Oncol (2013) 14(6):461-71. doi: 10.1016/S1470-2045(13)70130-X

16. Diéras V, Miles D, Verma S, Pegram M, Welslau M, Baselga J, et al. Trastuzumab emtansine versus capecitabine plus lapatinib in patients with previously treated HER2-positive advanced breast cancer (EMILIA): a descriptive analysis of final 
overall survival results from a randomised, open-label, phase 3 trial. Lancet Oncol (2017) 18(6):732-42. doi: 10.1016/S1470-2045(17)30312-1

17. Mancuso MR, Massarweh SA. Endocrine therapy and strategies to overcome therapeutic resistance in breast cancer. Curr Probl Cancer (2016) 40(2-4):95105. doi: 10.1016/j.currproblcancer.2016.09.001

18. Baselga J, Semiglazov V, van Dam P, Manikhas A, Bellet M, Mayordomo J, et al. Phase II randomized study of neoadjuvant everolimus plus letrozole compared with placebo plus letrozole in patients with estrogen receptor-positive breast cancer. J Clin Oncol (2009) 27(16):2630-7. doi: 10.1200/JCO.2008.18.8391

19. Bachelot T, Bourgier C, Cropet C, Ray-Coquard I, Ferrero JM, Freyer G, et al. Randomized phase II trial of everolimus in combination with tamoxifen in patients with hormone receptor-positive, human epidermal growth factor receptor 2-negative metastatic breast cancer with prior exposure to aromatase inhibitors: a GINECO study. J Clin Oncol (2012) 30(22):2718-24. doi: 10.1200/JCO.2011.39.0708

20. Piccart M, Hortobagyi GN, Campone M, Pritchard KI, Lebrun F, Ito Y, et al. Everolimus plus exemestane for hormone-receptor-positive, human epidermal growth factor receptor-2-negative advanced breast cancer: overall survival results from BOLERO-2dagger. Ann Oncol (2014) 25(12):2357-62. doi: 10.1093/annonc/mdu456

21. Gianni L, Bisagni G, Colleoni M, Del Mastro L, Zamagni C, Mansutti M, et al. Neoadjuvant treatment with trastuzumab and pertuzumab plus palbociclib and fulvestrant in HER2-positive, ER-positive breast cancer (NA-PHER2): an exploratory, open-label, phase 2 study. Lancet Oncol (2018) 19(2):249-56. doi: 10.1016/S1470-2045(18)30001-9

22. Hortobagyi GN, Stemmer SM, Burris HA, Yap YS, Sonke GS, Paluch-Shimon S, et al. Ribociclib as First-Line Therapy for HR-Positive, Advanced Breast Cancer. N Engl J Med (2016) 375(18):1738-48. doi: 10.1056/NEJMoa1609709

23. Arpino G, Wiechmann L, Osborne CK, Schiff R. Crosstalk between the estrogen receptor and the HER tyrosine kinase receptor family: molecular mechanism and clinical implications for endocrine therapy resistance. Endocr Rev (2008) 29(2):217-33. doi: 10.1210/er.2006-0045

24. Shou J, Massarweh S, Osborne CK, Wakeling AE, Ali S, Weiss H, et al. Mechanisms of tamoxifen resistance: increased estrogen receptor-HER2/neu cross-talk in ER/HER2-positive breast cancer. J Natl Cancer Inst (2004) 96 (12):926-35. doi: 10.1093/jnci/djh166

25. Johnston SRD, Hegg R, Im S-A, Park IH, Burdaeva O, Kurteva G, et al. Phase III, Randomized Study of Dual Human Epidermal Growth Factor Receptor 2 (HER2) Blockade With Lapatinib Plus Trastuzumab in Combination With an Aromatase Inhibitor in Postmenopausal Women With HER2-Positive, Hormone Receptor-Positive Metastatic Breast Cancer: ALTERNATIVE. J Clin Oncol (2018) 36(8):741-8. doi: 10.1200/JCO.2017.74.7824

26. Rimawi M, Ferrero J-M, Jdl H-R, Poole C, SD P, CK O, et al. First-Line Trastuzumab Plus an Aromatase Inhibitor, With or Without Pertuzumab, in Human Epidermal Growth Factor Receptor 2-Positive and Hormone Receptor-Positive Metastatic or Locally Advanced Breast Cancer (PERTAIN): A Randomized, Open-Label Phase II Trial. J Clin Oncol (2018) 36(28):2826-35. doi: 10.1200/JCO.2017.76.7863

27. Blanchard DK, Shetty PB, Hilsenbeck SG, Elledge RM. Association of surgery with improved survival in stage IV breast cancer patients. Ann Surg (2008) 247 (5):732-8. doi: 10.1097/SLA.0b013e3181656d32

28. Fields RC, Jeffe DB, Trinkaus K, Zhang Q, Arthur C, Aft R, et al. Surgical resection of the primary tumor is associated with increased long-term survival in patients with stage IV breast cancer after controlling for site of metastasis. Ann Surg Oncol (2007) 14(12):3345-51. doi: 10.1245/s10434-007-9527-0

29. Gnerlich J, Jeffe DB, Deshpande AD, Beers C, Zander C, Margenthaler JA. Surgical removal of the primary tumor increases overall survival in patients with metastatic breast cancer: analysis of the 1988-2003 SEER data. Ann Surg Oncol (2007) 14(8):2187-94. doi: 10.1245/s10434-007-9438-0

30. Lang JE, Tereffe W, Mitchell MP, Rao R, Feng L, Meric-Bernstam F, et al. Primary tumor extirpation in breast cancer patients who present with stage IV disease is associated with improved survival. Ann Surg Oncol (2013) 20 (6):1893-9. doi: 10.1245/s10434-012-2844-y

31. Pathy NB, Verkooijen HM, Taib NA, Hartman M, Yip CH. Impact of breast surgery on survival in women presenting with metastatic breast cancer. $\mathrm{Br} \mathrm{J}$ Surg (2011) 98(11):1566-72. doi: 10.1002/bjs.7650

32. Pons-Tostivint E, Kirova Y, Lusque A, Campone M, Geffrelot J, Mazouni C, et al. Survival Impact of Locoregional Treatment of the Primary Tumor in De Novo Metastatic Breast Cancers in a Large Multicentric Cohort Study: A Propensity Score-Matched Analysis. Ann Surg Oncol (2019) 26(2):356-65. doi: 10.1245/s10434-018-6831-9

33. Rashaan ZM, Bastiaannet E, Portielje JE, van de Water W, van der Velde S, Ernst MF, et al. Surgery in metastatic breast cancer: patients with a favorable profile seem to have the most benefit from surgery. Eur J Surg Oncol (2012) 38 (1):52-6. doi: 10.1016/j.ejso.2011.10.004

34. Ruiterkamp J, Ernst MF, van de Poll-Franse LV, Bosscha K, Tjan-Heijnen VC, Voogd AC. Surgical resection of the primary tumour is associated with improved survival in patients with distant metastatic breast cancer at diagnosis. Eur J Surg Oncol (2009) 35(11):1146-51. doi: 10.1016/ j.ejso.2009.03.012

35. Shibasaki S, Jotoku H, Watanabe K, Takahashi M. Does primary tumor resection improve outcomes for patients with incurable advanced breast cancer? Breast (2011) 20(6):543-7. doi: 10.1016/j.breast.2011.06.006

36. Wang K, Shi Y, Li ZY, Xiao YL, Li J, Zhang X, et al. Metastatic pattern discriminates survival benefit of primary surgery for de novo stage IV breast cancer: A real-world observational study. Eur J Surg Oncol (2019) 45(8):136472. doi: 10.1016/j.ejso.2019.02.013

37. Neuman HB, Morrogh M, Gonen M, Van Zee KJ, Morrow M, King TA. Stage IV breast cancer in the era of targeted therapy: does surgery of the primary tumor matter? Cancer (2010) 116(5):1226-33. doi: 10.1002/cncr.24873

38. Soran A, Ozmen V, Ozbas S, Karanlik H, Muslumanoglu M, Igci A, et al. Randomized Trial Comparing Resection of Primary Tumor with No Surgery in Stage IV Breast Cancer at Presentation: Protocol MF07-01. Ann Surg Oncol (2018) 25(11):3141-9. doi: 10.1245/s10434-018-6494-6

39. Badwe R, Hawaldar R, Nair N, Kaushik R, Parmar V, Siddique S, et al. Locoregional treatment versus no treatment of the primary tumour in metastatic breast cancer: an open-label randomised controlled trial. Lancet Oncol (2015) 16(13):1380-8. doi: 10.1016/S1470-2045(15)00135-7

40. Shien T, Doihara H. Resection of the primary tumor in stage IV breast cancer. World J Clin Oncol (2014) 5(2):82-5. doi: 10.5306/wjco.v5.i2.82

41. Cady B, Nathan NR, Michaelson JS, Golshan M, Smith BL. Matched pair analyses of stage IV breast cancer with or without resection of primary breast site. Ann Surg Oncol (2008) 15(12):3384-95. doi: 10.1245/s10434-008-0085-x

42. Lin C, Wu J, Ding S, Goh C, Andriani L, Lu S, et al. Subdivision of M1 Stage for De Novo Metastatic Breast Cancer to Better Predict Prognosis and Response to Primary Tumor Surgery. J Natl Compr Canc Netw (2019) 17 (12):1521-8. doi: 10.6004/jnccn.2019.7332

43. Wang Z, Wang H, Sun X, Fang Y, Lu SS, Ding SN, et al. A Risk Stratification Model for Predicting Overall Survival and Surgical Benefit in Triple-Negative Breast Cancer Patients With de novo Distant Metastasis. Front Oncol (2020) 10:14. doi: $10.3389 /$ fonc. 2020.00014

Conflict of Interest: The authors declare that the research was conducted in the absence of any commercial or financial relationships that could be construed as a potential conflict of interest.

Copyright $\odot 2020 \mathrm{Liu}, \mathrm{Wu}$, Lin, Andriani, Ding, Shen and Zhu. This is an open-access article distributed under the terms of the Creative Commons Attribution License (CC BY). The use, distribution or reproduction in other forums is permitted, provided the original author(s) and the copyright owner(s) are credited and that the original publication in this journal is cited, in accordance with accepted academic practice. No use, distribution or reproduction is permitted which does not comply with these terms. 